\title{
Comparison of Er:YAG Laser and Hand Instrumentation on the Attachment of Cultured Human Gingival Fibroblasts to Periodontally Involved Root Surfaces
}

\author{
Mohammad Reza Talebi-Ardakani ${ }^{1}$, Maryam Torshabi², Elahe Karami ${ }^{3}$, Nazanin Vajar ${ }^{4}$, Zeinab Rezaei \\ Esfahrood $^{1 *}$, Mansour Meimandi ${ }^{1}$, Seyed Masoud Mojahedi ${ }^{5}$ \\ ${ }^{1}$ Department of Periodontics, School of Dentistry, Shahid Beheshti University of Medical Sciences, Tehran, Iran \\ ${ }^{2}$ Department of Dental Biomaterials, School of Dentistry, Shahid Beheshti University of Medical Sciences, Tehran, Iran \\ ${ }^{3}$ Department of Periodontics, School of Dentistry, Yazd University of Medical Sciences, Yazd, Iran \\ ${ }^{4}$ School of Dentistry, International Branch, Shahid Beheshti University of Medical Sciences, Tehran, Iran \\ ${ }^{5}$ RWTH University, Aachen, Germany
}

\author{
*Correspondence to \\ Zeinab Rezaei Esfahrood; \\ Assistant Professor, Department of \\ Periodontics, School of Dentistry, \\ Shahid Beheshti University of \\ Medical Sciences, Tehran, Iran. \\ Tel: +982126802751 \\ Fax: +98 2122403194 \\ Email: zre538@yahoo.com
}

Published online 29 August 2017

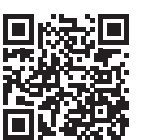

\begin{abstract}
Introduction: The present study compared the effects of erbium-doped yttrium aluminium garnet (Er:YAG) laser and hand instrumentation on the attachment of human gingival fibroblast (HGF) cells to periodontally involved root surfaces.

Methods: A total of 40 tooth specimens were collected and treated in four distinct groups: scaled and root planed with hand instruments, scaled with Er:YAG laser, treated with a combination of hand instruments and Er:YAG laser and non-treated control group. The attachment and proliferation rate of HGF were assessed using MTT assay and scanning electron microscope (SEM) examination was used for cell morphological evaluation.

Results: The MTT (3-[4, 5-dimethylthiazol-2-yl]-2, 5 diphenyl tetrazolium bromide) assay showed significant decrease in HGF cell viability in both hand instruments only and combination treated teeth specimens compared to control specimens $(P<0.05), 24$ hours after cell seeding. However, at time 48 , the cell viability of attached cells in these 2 treated groups was almost similar to control. In contrast, at 24 and 48 hours after cell seeding, viability of attached cells was higher than control in Er:YAG laser treated only specimens $(P<0.05)$. According to SEM study, the laser treated specimens showed more surface roughness.

Conclusion: Er:YAG laser increased attachment and proliferation of HGF cells in comparison to the hand instruments method.

Keywords: Scaling; Root planning; Er:YAG laser; Fibroblast; Viability; Attachment.
\end{abstract}

\section{Introduction}

Periodontitis is one of the most prevalent diseases, leading to severe loss of supporting periodontal tissues. ${ }^{1}$ A primary goal of non-surgical periodontal therapy can be defined as thorough removal of bacterial deposits to prevent disease progression. ${ }^{2}$ Scaling and root planing (SRP) are commonly used for root debridement ${ }^{3}$ and usually accomplished by hand instruments and ultrasonic scalers. ${ }^{4}$ Though, bacterial deposits are not always completely removed by conventional mechanical instruments and the formation of a smear layer containing bacteria, bacterial endotoxins and diseased root cementum after mechanical treatment may hinder reattachment of cells to the root surface. ${ }^{5-9}$ Recently, laser therapy has been proposed as an adjunctive treatment to root surface debridement due to its ability to obtain excellent tissue ablation, detoxification and strong bactericidal effects. ${ }^{10}$ Among all lasers applied in dentistry, erbium yttrium aluminum garnet (Er:YAG) laser has been considered as the most promising laser for periodontal therapy. Based on many studies, Er:YAG laser used for scaling can effectively remove subgingival calculus without leading to any thermal alterations, such as carbonization, melting, or cracking, which are usually observed following carbon dioxide (CO2) and neodymium-doped yttrium aluminium garnet (Nd:YAG) laser irradiation. ${ }^{11-14}$

In the present study, the effects of Er:YAG Laser and hand instrumentation methods on human gingival fibroblast (HGF) cells attachment to treated root surfaces and subsequently on morphology, viability and proliferation of 
attached cells were compared.

\section{Materials and Methods}

Specimen Collection and Preparation

A total of 20 periodontally-involved single-rooted teeth with no signs of caries were collected following teeth extraction. The teeth were gently cleaned and then kept in normal saline solution at room temperature. The crowns and apical parts of the roots were cut off perpendicular to the long axis of the teeth, and the roots were further sectioned longitudinally in a bucco-lingual plane using a diamond disk running at low speed with sterile water coolant.

A total of 40 specimens were prepared and sterilized with ethanol $70 \%$ and UV radiation (20 minutes for each side). Then, they were washed with phosphate buffered saline (BPS) several times. The specimens were randomly divided into 4 groups: (1) 10 specimens were washed with sterile saline solution (control group), (2) 10 specimens were scaled and root planned with hand instruments (Gracey Curette, Hu-Friedy Co. Ltd., Chicago, IL), (3) 10 specimens were treated with Er:YAG laser (Smart 2940D Plus, Deka, Calenzana, Italy) with a wavelength of 2.94 $\mu \mathrm{m}$, used at $450 \mathrm{~mJ} /$ pulse at $10 \mathrm{~Hz}$ equivalent to the energy densities of $94 \mathrm{~J} / \mathrm{cm}^{2}$ per pulse. The tip of the handpiece (N30202) was applied perpendicularly to the root surface under water irrigation, and (4) final 10 specimens were treated with both method (instrumental and laser treatment). Irradiation for the last group was performed immediately after scaling with an energy level of 80 for 30 seconds.

\section{Cell Culture}

The HGF cell line was obtained from the National Cell Bank of Iran (NCBI code: C-165) (Pasteur Institute, Tehran). The cells were grown in Dulbecco's modified Eagle medium (DMEM) complemented with $10 \%$ fetal bovine serum (FBS) and 1\% antibiotic-antimycotic (Gibco, UK) in $5 \% \mathrm{CO}_{2}$ at $37^{\circ} \mathrm{C}$ incubator. The sterilized specimens were placed in wells of 48 -well culture plates (SPL, Korea) and then HGF cells were seeded on them at a density of 2 $\times 10^{4}$ cells/specimen.

\section{MTT Assay}

The MTT test was employed in this study to quantitatively assess viable cell attachment and proliferation. After 24 and 48 hours incubation, the specimens were transferred to new plates and were gently rinsed twice with sterile PBS solution and were incubated with fresh culture medium containing $10 \%$ MTT dye solution $(0.5 \mathrm{mg} / \mathrm{mL}$ stock solution) (Sigma-Aldrich, Germany) for 3 hours at $37^{\circ} \mathrm{C}$. After completing incubation, the medium of each well was aspirated and replaced with the same volume of dimethyl sulfoxide (DMSO) solvent and further incubated for 30 minutes in room temperature (gentle shaking) to dissolve purple formazan crystals. Then $100 \mu \mathrm{L}$ of purple solution in each well were transferred to each well of a 96well plate (6 repetitions), and the optical density (OD) of each well was measured using an Elisa reader instrument (Anthos 2020, Austria) at 570 and $620 \mathrm{~nm}$ wavelength.

\section{Scanning Electron Microscopy}

For qualitative evaluation of cell morphology and attachment, 24 hours after cell seeding on the surface of the tooth specimens, the considered specimens were rinsed with PBS and then fixed in $2.5 \%$ glutaraldehyde solution (Merck, Germany) for 24 hours at $4^{\circ} \mathrm{C}$. After removal of glutaraldehyde and several rinsing with distilled water, $1 \%$ osmium solution (TAAB, UK) was added ( 2 hours incubation at room temperature). The specimens were washed with distilled water and then dehydrated through a graded series of ethanol $(30 \%, 50 \%, 70 \%, 80 \%, 90 \%$, and $100 \%$ for at least 15 minutes per step). Finally, gold was sputtered on the samples before scanning electron microscopy (SEM) (KYKY-EM3200, Beijing, China).

\section{Statistical Analysis}

The quantitative experiments were repeated 2 times and the results were presented as mean \pm standard deviation (SD). Differences between groups were analyzed by GraphPad Prism (V.6.01) (GraphPad software Inc., La Jolla, USA) using one-way analysis of variance (ANOVA) followed by a post hoc Turkey test. A $P$ value $<0.05$ was considered significant and determined by an asterisk in the corresponding figures.

\section{Results}

Effect of Root Surface Treatments on the Viability and Proliferation of HGF Cells

The number of metabolically viable cells attached to treated-tooth surfaces was evaluated with MTT assay after 24 (initial attachment) and 48 (proliferation) hours of culture and compared to untreated tooth surfaces (control). As seen in Figure 1A, both scaled Gracey curette (hand instrumentation treatment) $(54.5 \pm 3.1 \%)$ and scaled Grac-

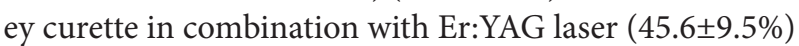
treated surfaces (no significant differences between 2 different groups) exhibited a significantly lower viability percentage of attached cells compared to control group (viability 100\%), 24 hours after cell seeding on teeth surfaces. Conversely, statistically significant increase in viable attached cells was detected in Er:YAG laser treated surfaces $(138 \pm 25.7 \%)$ compared to control (100\%) and also compared to both scaled Gracey curette and scaled Gracey curette in combination with Er:YAG laser treated surfaces.

As seen in Figure 1B (48 hours after cell seeding on teeth surfaces) the Er:YAG laser treated surfaces revealed a significant increased cell viability $(197.1 \pm 44.6 \%)$ compared to control (100\%), scaled Gracey curette $(87.6 \pm 7.9 \%$, no significant differences compared to control) and scaled Gracey curette in combination with Er:YAG laser $(109.7 \pm 24.8 \%$, no significant differences compared to control) treated surfaces. No statistically significant differences in cell viability was observed between scaled Gracey curette and scaled Gracey curette in combination 

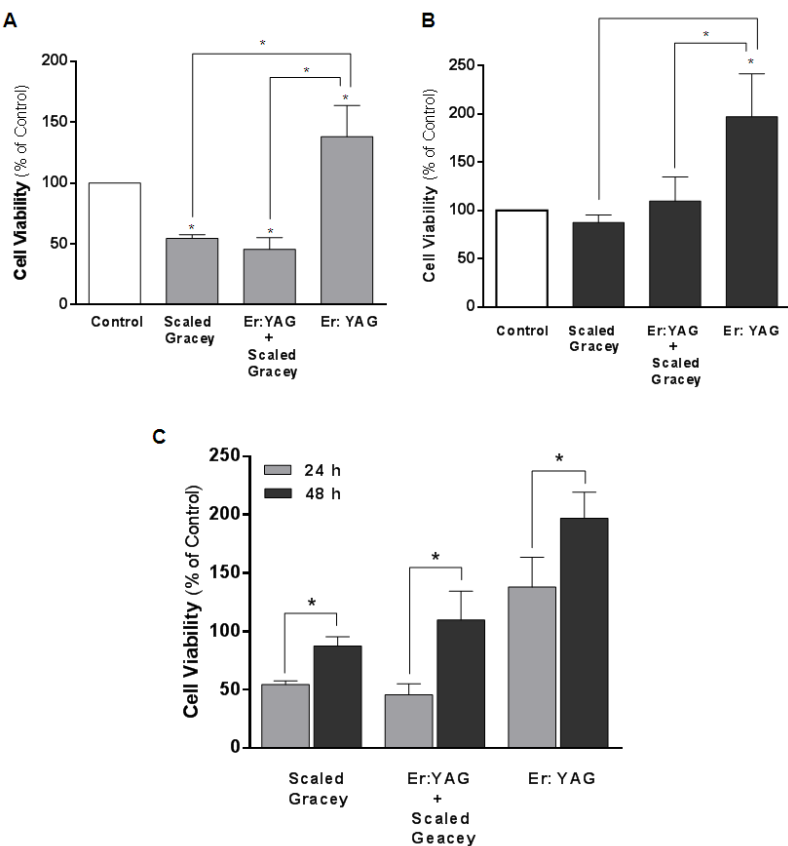

Figure 1. The effect of scaled Gracey curette (hand instrumentation treatment) only, scaled Gracey curette in combination with Er:YAG laser and Er:YAG laser only treatment on viability of attached HGF cells at 24 hours (A) and 48 hours (B) after attachment, compared to control group (non-treated teeth surfaces, viability $100 \%$ ). The timedependent increase in cell viability and proliferation is also indicated (C) $\left({ }^{*} P<0.05\right)$.

with Er:YAG laser.

Furthermore, time-dependent increase (48 hours after cell attachment on root surfaces compared to 24-hours attachment) in cell viability and proliferation was observed in all three treated groups (Figure 1C).

Effect of Root Surface Treatments on the Morphology of HGF Attached Cells

The SEM micrographs ( $\times 260-640$ magnification $)$ of attached HGF cells on treated and non-treated root surfaces are seen in Figure 2. The morphology of fibroblast cells was normal in all groups. The specimens treated by Er:YAG laser irradiation presented the most irregular surfaces (roughness). The scaled Gracey curette treated surfaces exhibited a rough topography with a significant number of attached fibroblasts.

\section{Discussion}

One of the most important objectives of periodontal treatment is connective tissue attachment on root surfaces previously damaged by periodontitis. The elimination of subgingival microbiota and bacterial endotoxins from root surfaces is necessary for migration and attachment of fibroblasts and it is often impossible to achieve by mechanical instrumentation. ${ }^{9,15,16}$ Several studies have indicated that $\mathrm{CO}_{2}$, Nd:YAG and Er:YAG lasers could increase the efficiency of root debridement and detoxification. ${ }^{13,17-20} \mathrm{CO}_{2}$ and Nd:YAG lasers have been effectively applied for oral soft tissue surgical procedures, ${ }^{21-23}$ where-
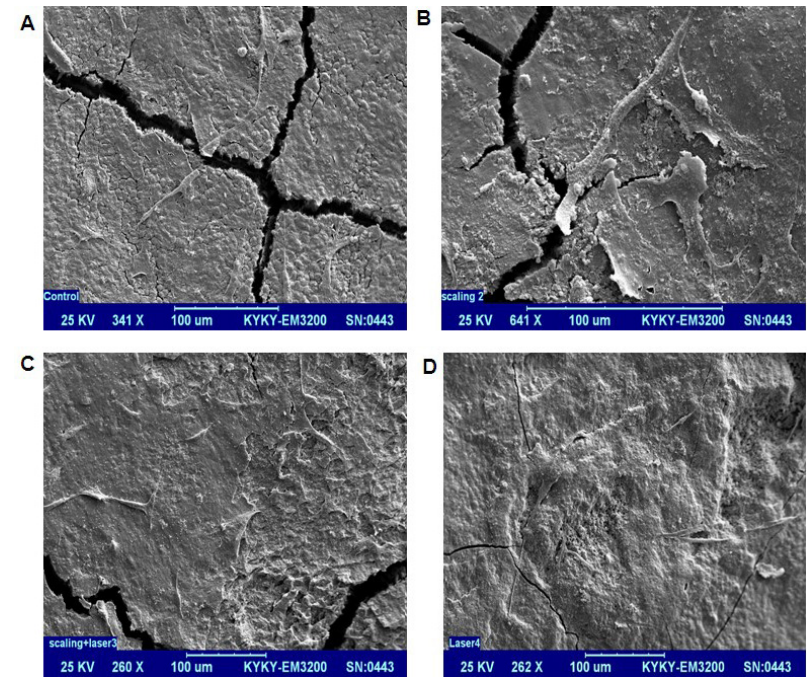

Figure 2. Scanning electron microscopic pictures of HGF cells, 24 hours after attachment on root surfaces: control non-treated (A), scaled Gracey curette treated (B), combination of scaled Gracey curette and Er:YAG laser treated (C), Er:YAG laser treated (D).

as the Er:YAG laser can be used to ablate hard tissue conveniently and precisely. ${ }^{14,17,24}$

In this study, we examined the attachment and proliferation of HGF to root surface after Er:YAG debridement. Er:YAG laser treatment resulted in a high surface roughness which probably enhance adhesion of fibroblasts. Our results are in agreement with the study by Bolortuya. ${ }^{25}$ Surface topography is an important factor in the adhesion of fibroblast cells ${ }^{26}$ and some previous studies reported that fibroblasts were more likely to attach to rough-surfaced than to smooth-surfaced specimens. ${ }^{27}$ This surface alteration obtained by the Er:YAG laser irradiation probably exposes chemical root substances that are highly selective for chemotaxis of fibroblasts. ${ }^{28}$ Also, it seems that the microstructure of the surface irradiated by laser would be useful for blood clot and fibrin adhesion on the root surface and result in increased initial cell and tissue attachment. ${ }^{29,30}$ However, some studies reported that fibroblasts favor smooth textured surfaces. ${ }^{31,32}$ Furthermore, Schwarz et al showed that periodontally infected root surfaces hinder the adherence of periodontal ligament (PDL) fibroblasts and Er:YAG laser treatment with effective elimination of subgingival calculus and infected cementum, created a biocompatible surface for new cell reattachment. ${ }^{33}$ Similar to our results, several studies indicate more rapid adhesion and proliferation of fibroblasts on lased surfaces compared with mechanically instrumented surfaces. ${ }^{33-35}$ However, Maruyama et al demonstrated that Er:YAG laser-treated surface tended to inhibit the primary attachment of PDL cells. ${ }^{36}$ This dissimilarity is probably due to differences in laser parameters and experimental design. Increasing power and density is related to surface irregularities when using different laser modalities. ${ }^{37}$ Feist et al investigated the human gingival fibroblasts adhesion and proliferation on periodontally diseased root surfaces irradiated by Er:YAG laser. The surfaces treated with $100 \mathrm{~mJ} /$ 
pulse Er:YAG laser irradiation indicated slower adhesion and proliferation of cells than surfaces irradiated with 60 $\mathrm{mJ} /$ pulse Er:YAG laser. ${ }^{34}$ Increased power may also result in creation of a superficial layer on the root surfaces, melted minerals and cavitation defects, ${ }^{37}$ which prevent the PDL cell attachment. ${ }^{38}$ Hence, it is important to identify the ideal irradiation condition of the Er:YAG laser for improved cell attachment to root surfaces. ${ }^{25}$

Our investigation has shown that the Er:YAG laser treated surfaces revealed the highest cell viability/proliferation and the samples treated by laser irradiation presented the most irregular surfaces, which can lead to increased adhesion and growth of fibroblasts on laser-irradiated surfaces. We believe that our results might help clinicians to choose the best laser settings in various clinical conditions. However, more studies are required in order to evaluate the clinical effectiveness of low level laser. In conclusion, Er:YAG laser radiation produced a roughened root surface and increased fibroblast attachment/proliferation compared to scaled Gracey curette treatment.

\section{Acknowledgements}

This paper is taken from a thesis submitted in partial fulfillment of the requirements for the Degree of dentistry in International Branch Shahid Beheshti University of Medical Sciences, Tehran-Iran.

\section{Ethical Considerations}

This study was approved by ethics review committee of Shahid Beheshti University of Medical Sciences.

\section{Conflict of Interests}

None.

\section{References}

1. O'Leary TJ. The impact of research on scaling and root planing. J Periodontol. 1986;57(2):69-75.

2. Kepic TJ, O’Leary TJ, Kafrawy AH. Total calculus removal: an attainable objective? J Periodontol. 1990;61(1):16-20.

3. Badersten A, Nilveus R, Egelberg J. Effect of nonsurgical periodontal therapy. II. Severely advanced periodontitis. J Clin Periodontol. 1984;11(1):63-76.

4. Tunkel J, Heinecke A, Flemmig TF. A systematic review of efficacy of machine-driven and manual subgingival debridement in the treatment of chronic periodontitis. $J$ Clin Periodontol. 2002;29 Suppl 3:72-81.

5. O'Leary TJ, Kafrawy AH. Total cementum removal: a realistic objective? J Periodontol. 1983;54(4):221-226.

6. Adriaens PA, Edwards CA, De Boever JA, Loesche WJ. Ultrastructural observations on bacterial invasion in cementum and radicular dentin of periodontally diseased human teeth. J Periodontol. 1988;59(8):493-503.

7. Oda S, Nitta H, Setoguchi T, Izumi Y, Ishikawa I. Current concepts and advances in manual and power-driven instrumentation. Periodontol 2000. 2004;36:45-58. doi:10.1111/j.1600-0757.2004.03674.x.

8. Polson AM, Frederick GT, Ladenheim S, Hanes PJ. The production of a root surface smear layer by instrumentation and its removal by citric acid. J Periodontol. 1984;55(8):443446.
9. Aleo JJ, De Renzis FA, Farber PA, Varboncoeur AP. The presence and biologic activity of cementum-bound endotoxin. J Periodontol. 1974;45(9):672-675.

10. Aoki A, Sasaki KM, Watanabe H, Ishikawa I. Lasers in nonsurgical periodontal therapy. Periodontol 2000. 2004;36:59-97.

11. Aoki A, Ando $\mathrm{Y}$, Watanabe $\mathrm{H}$, Ishikawa I. In vitro studies on laser scaling of subgingival calculus with an erbium:YAG laser. J Periodontol. 1994;65(12):1097-1106.

12. Folwaczny M, Mehl A, Haffner C, Benz C, Hickel R. Root substance removal with Er:YAG laser radiation at different parameters using a new delivery system. J Periodontol. 2000;71(2):147-155.

13. Israel M, Cobb CM, Rossmann JA, Spencer P. The effects of CO2, Nd:YAG and Er:YAG lasers with and without surface coolant on tooth root surfaces. An in vitro study. J Clin Periodontol. 1997;24(9 Pt 1):595-602.

14. Schwarz F, Putz N, Georg T, Reich E. Effect of an Er:YAG laser on periodontally involved root surfaces: an in vivo and in vitro SEM comparison. Lasers in surgery and medicine. Lasers Surg Med. 2001;29(4):328-335.

15. Hatfield CG, Baumhammers A. Cytotoxic effects of periodontally involved surfaces of human teeth. Arch Oral Biol. 1971;16(4):465-468.

16. Waerhaug J. Healing of the dento-epithelial junction following subgingival plaque control. II: As observed on extracted teeth. J Periodontol. 1978;49(3):119-134.

17. Sasaki KM, Aoki A, Ichinose S, Ishikawa I. Morphological analysis of cementum and root dentin after Er:YAG laser irradiation. Lasers Surg Med. 2002;31(2):79-85.

18. Crespi R, Romanos GE, Barone A, Sculean A, Covani U. Er:YAG laser in defocused mode for scaling of periodontally involved root surfaces: an in vitro pilot study. J Periodontol. 2005;76(5):686-90. doi:10.1902/jop.2005.76.5.686.

19. Gómez C, Costela A, Garcia-Moreno I, Garcia JA. In vitro evaluation of Nd:YAG laser radiation at three different wavelengths $(1064,532$, and $355 \mathrm{~nm})$ on calculus removal in comparison with ultrasonic scaling. Photomed Laser Surg. 2006;24(3):366-76. doi:10.1089/pho.2006.24.366.

20. Barone A, Covani U, Crespi R, Romanos GE. Root surface morphological changes after focused versus defocused CO2 laser irradiation: a scanning electron microscopy analysis. J Periodontol. 2002;73(4):370-373.

21. Morlock BJ, Pippin DJ, Cobb CM, Killoy WJ, Rapley JW. The effect of Nd:YAG laser exposure on root surfaces when used as an adjunct to root planing: an in vitro study. $J$ Periodontol. 1992;63(7):637-641.

22. Mindermann A, Niemz MH, Eisenmann L, Loesel FH, Bille JF. Comparison of three different laser systems for application in dentistry. Dent Appl Lasers. 1993;68(31):2-9.

23. Keller U, Hibst R. Lasers in dentistry: clinical application today and tomorrow. Dent Appl Lasers. 1993;2(31):68-76.

24. Aoki A, Ishikawa I, Yamada T, et al. Comparison between Er:YAG laser and conventional technique for root caries treatment in vitro. J Dent Res. 1998;77(6):1404-1414.

25. Bolortuya G, Ebihara A, Ichinose S, et al. Effects of dentin surface modifications treated with Er:YAG and Nd:YAG laser irradiation on fibroblast cell adhesion. Photomed Laser Surg. 2012;30(2):63-70. doi: 10.1089/pho.2011.3132.

26. Brunette DM. The effects of implant surface topography on the behavior of cells. Int J Oral Maxillofac Implants. 1988;3(4):231-246.

27. Babay N. Attachment of human gingival fibroblasts to 
periodontally involved root surface following scaling and/ or etching procedures: a scanning electron microscopy study. Braz Dent J. 2001;12(1):17-21.

28. Fernyhough W, Page RC. Attachment, growth and synthesis by human gingival fibroblasts on demineralized or fibronectin-treated normal and diseased tooth roots. $J$ Periodontol. 1983;54(3):133-140.

29. Pourzarandian A, Watanabe H, Aoki A, et al. Histological and TEM examination of early stages of bone healing after Er:YAG laser irradiation. Photomed Laser Surg. 2004;22(4):342-350. doi:10.1089/pho.2004.22.342.

30. Theodoro LH, Sampaio JE, Haypek P, Bachmann L, Zezell DM, Garcia VG. Effect of Er:YAG and Diode lasers on the adhesion of blood components and on the morphology of irradiated root surfaces. J Periodontal Res. 2006;41(5):381390. doi:10.1111/j.1600-0765.2005.00846.x.

31. Kononen M, Hormia M, Kivilahti J, Hautaniemi J, Thesleff I. Effect of surface processing on the attachment, orientation, and proliferation of human gingival fibroblasts on titanium. J Biomed Mater Res A. 1992;26(10):1325-1341.

32. Bowers KT, Keller JC, Randolph BA, Wick DG, Michaels CM. Optimization of surface micromorphology for enhanced osteoblast responses in vitro. Int J Oral Maxillofac Implants. 1992;7(3):302-310.

33. Schwarz F, Aoki A, Sculean A, Georg T, Scherbaum W,
Becker J. In vivo effects of an Er:YAG laser, an ultrasonic system and scaling and root planing on the biocompatibility of periodontally diseased root surfaces in cultures of human PDL fibroblasts. Lasers Surg Med. 2003;33(2):140-147.

34. Feist IS, De Micheli G, Carneiro SR, Eduardo CP, Miyagi $S$, Marques MM. Adhesion and growth of cultured human gingival fibroblasts on periodontally involved root surfaces treated by Er:YAG laser. J Periodontol. 2003;74(9):13681375.

35. Crespi R, Romanos GE, Cassinelli C, Gherlone E. Effects of Er:YAG laser and ultrasonic treatment on fibroblast attachment to root surfaces: an in vitro study. J Periodontol. 2006;77(7):1217-1222. doi:10.1902/jop.2006.050416.

36. Maruyama H, Aoki A, Sasaki KM, et al. The effect of chemical and/or mechanical conditioning on the Er:YAG lasertreated root cementum: analysis of surface morphology and periodontal ligament fibroblast attachment. Lasers Surg Med. 2008;40(3):211-222. doi:10.1002/lsm.20609.

37. Cobb CM. Lasers in periodontics: a review of the literature. J Periodontol. 2006;77(4):545-564. doi:10.1902/ jop.2006.050417.

38. Fayad MI, Hawkinson R, Daniel J, Hao J. The effect of CO2 laser irradiation on PDL cell attachment to resected root surfaces. Oral Surg Oral Med Oral Pathol Oral Radiol Endod. 2004;97(4):518-523. doi:10.1016/S1079210403006814. 